\title{
Changing correlation structures of the Northern Hemisphere atmospheric circulation from 1000 to $2100 \mathrm{AD}$
}

\author{
C. C. Raible $^{1,2}$, F. Lehner ${ }^{1,2}$, J. F. González-Rouco ${ }^{3}$, and L. Fernández-Donado ${ }^{3}$ \\ ${ }^{1}$ Climate and Environmental Physics, University of Bern, Bern, Switzerland \\ ${ }^{2}$ Oeschger Centre for Climate Change Research, Bern, Switzerland \\ ${ }^{3}$ Instituto de Geociencias (UCM-CSIC), Facultad de CC. Fisicas, Universidad Complutense de Madrid, Madrid, Spain
}

Correspondence to: C. C. Raible (raible@climate.unibe.ch)

Received: 24 July 2013 - Published in Clim. Past Discuss.: 28 August 2013

Revised: 20 December 2013 - Accepted: 4 February 2014 - Published: 19 March 2014

\begin{abstract}
Atmospheric circulation modes are important concepts in understanding the variability of atmospheric dynamics. Assuming their spatial patterns to be fixed, such modes are often described by simple indices from rather short observational data sets. The increasing length of reanalysis products allows these concepts and assumptions to be scrutinised. Here we investigate the stability of spatial patterns of Northern Hemisphere teleconnections by using the Twentieth Century Reanalysis as well as several control and transient millennium-scale simulations with coupled models. The observed and simulated centre of action of the two major teleconnection patterns, the North Atlantic Oscillation (NAO) and to some extent the Pacific North American (PNA), are not stable in time. The currently observed dipole pattern of the NAO, its centre of action over Iceland and the Azores, split into a north-south dipole pattern in the western Atlantic with a wave train pattern in the eastern part, connecting the British Isles with West Greenland and the eastern Mediterranean during the period 1940-1969 AD. The PNA centres of action over Canada are shifted southwards and over Florida into the Gulf of Mexico during the period 1915-1944 AD. The analysis further shows that shifts in the centres of action of either teleconnection pattern are not related to changes in the external forcing applied in transient simulations of the last millennium. Such shifts in their centres of action are accompanied by changes in the relation of local precipitation and temperature with the overlying atmospheric mode. These findings further undermine the assumption of stationarity between local climate/proxy variability and large-scale
\end{abstract}

dynamics inherent when using proxy-based reconstructions of atmospheric modes, and call for a more robust understanding of atmospheric variability on decadal timescales.

\section{Introduction}

The complexity of the large-scale atmospheric flow (Lorenz, 1967) and the associated long-term climate variability are often simplified by characterising the atmospheric circulation using so-called modes of variability. These modes refer to physically meaningful teleconnection patterns, which connect distant and coherently varying regions with each other, and are often characterised by a time-varying index and a fixed spatial pattern (Stephenson et al., 2003). Since the late 19th century, indices have been used to identify regions of coherent climate variability (mainly temperature, precipitation, and pressure) and correlation analysis has been applied to observations in order to explore teleconnections (Hann, 1890; Defant, 1924). Such teleconnections originate from inphase variability that takes place at different locations due to either waves (e.g. Rossby waves) or advection of physical properties (e.g. temperature, humidity, etc.) by air masses (e.g. Wanner et al., 2001; Hurrell et al., 2004; Pinto and Raible, 2012).

Teleconnection patterns can also consist of two or more anti-correlated centres of action. Among others, the most important ones in the Northern Hemisphere boreal winter are the North Atlantic Oscillation (NAO) and the Pacific 
North America (PNA) patterns (Wallace and Gutzler, 1981; Barnston and Livezey, 1987). The NAO is the leading mode of the pressure field in the North Atlantic region, with two barotropic and anti-correlated centres of action: one over Iceland and the other over the Azores which extends to the Iberian Peninsula (e.g. Hurrell, 1995). The PNA is mainly manifested in the mid-troposphere and represents a wave train with centres over the tropical Pacific, the Aleutian Islands, northern Canada and Florida in the $500 \mathrm{hPa}$ geopotential height field (Wallace and Gutzler, 1981; Barnston and Livezey, 1987). These pressure patterns modulate the atmospheric flow (e.g. Woollings et al., 2010b) and control cyclone activity and changes in other climate variables (e.g. temperature and precipitation) at regional and local scales (Hurrell, 1995; Hurrell and Deser, 2009).

The inherent simplicity of these atmospheric modes, the societal relevance, and the relationships to variables such as temperature and precipitation have attracted the interests of the climate proxy and reconstruction community over recent decades. The aim has been to extend the time series of such modes beyond the instrumental period by using proxy data from archives (e.g. tree rings, stalagmites, ice cores) in order to deepen our understanding of the low-frequency variability of such modes (e.g. Casty et al., 2007). This has led to a number of reconstructions for the NAO (e.g. Luterbacher et al., 1999; Cook et al., 2002; Mann, 2002; Trouet et al., 2009) and the PNA indices (Moore et al., 2002; Trouet and Taylor, 2010), albeit often with contradicting time evolution prior to the instrumental era (Schmutz et al., 2000; Pinto and Raible, 2012). One source of uncertainty arises from the proxies themselves, as temperature-sensitive proxies seem to be less reliable than precipitation-sensitive proxy records for reconstructing atmospheric indices (Zorita and Gonzalez-Rouco, 2002). Additionally, regional biases of proxy records and the regional representation of proxy sites are important. For instance, Lehner et al. (2012b) recently showed in climate model simulations and reanalysis products that the constraint by only two precipitation-sensitive proxies at two different sites used in one reconstruction (Trouet et al., 2009) is insufficient to reliably reconstruct the simulated past NAO behaviour. Moreover, the selection of suitable proxy locations in reconstructing atmospheric modes of variability may have been geographically biased toward those regions affected by the NAO in the 20th century (Cook et al., 2002).

One conceptual shortcoming of teleconnection patterns is that their centres of action are often interpreted to be fixed in space, an inherent characteristic of index definitions. Additionally, stationarity in the relation between the proxy records and the atmospheric circulation is a basic assumption of past reconstructions of such indices. However, there is growing evidence that this interpretation and the assumption are not always trustworthy. Ulbrich and Christoph (1999) found a systematic north-eastward shift of the northern centre of action of the NAO in climate model projections for the 21 st century, indicating that at least the simulated position of the pressure centres is not stable in time. Investigating the low-frequency characteristics of Northern Hemispheric teleconnection patterns, a series of studies have already found structural changes (in shape and position) of these patterns and that these changes are connected to differences in the atmosphere-ocean coupling (Raible et al., 2001, 2004; Luksch et al., 2005). Focusing on longer timescales, Raible et al. (2006) showed evidence that the southern centre of action of the NAO is relocated from its present state around the Azores/Lisbon to the central Mediterranean when analysing European pressure field reconstructions for the past 500 years (Luterbacher et al., 2002) as well as control simulations with coupled climate models. Franzke and Feldstein (2005) interpreted the teleconnection patterns as a continuum of superposed combinations of different atmospheric circulation modes, e.g. for the North Atlantic a combination of the NAO, the East Atlantic (EA) and the Scandinavian (SCA) patterns (Moore et al., 2013). Such combinations can lead to instability in the centres of action and could influence relationships between the large-scale circulation and proxy records (Raible et al., 2006).

The aim of this study is to investigate the spatio-temporal behaviour of teleconnection patterns in the Northern Hemisphere for the last 1000 years in control and transient simulations with two coupled climate models. The correlation structures are thereby determined by the teleconnectivity measure first introduced by Wallace and Gutzler (1981). The results are compared with reanalysis data (Compo et al., 2011). The transient simulations are further used to assess the response of the spatio-temporal behaviour to the external forcing applied. Additionally, impacts of the spatio-temporal behaviour of teleconnection patterns on fields relevant for the proxy reconstruction community are discussed.

Section 2 briefly gives an overview of the data sets, the models, and simulations used in this study. The teleconnection patterns are introduced and their spatial variability is discussed in Sect. 3. Then, the impact of the changing correlation structures on potential proxy sites is illustrated, highlighting potential limitations of the ability of current proxies to reconstruct such changes (Sect. 4). Finally, concluding remarks are presented in Sect. 5.

\section{Data, models, and experimental design}

In this study we use the Twentieth Century Reanalysis (TCR, version 2; Compo et al., 2006, 2011, NOAA/OAR/ESRL PSD, Boulder, Colorado, USA). These data are generated at T63 horizontal resolution (i.e. a triangular spectral truncation at wave number 63) and provided on a regular grid of $2.5^{\circ} \times 2.5^{\circ}$. The data are interpolated to T30/T31 (roughly $3.75^{\circ} \times 3.75^{\circ}$ ) to be comparable with the model data. TCR consists of an ensemble of 56 members and the ensemble mean for the period 1871-2010. Both the ensemble mean and the individual members of the $500 \mathrm{hPa}$ geopotential height 
Table 1. Overview of simulations available for the analysis.

\begin{tabular}{lllrr}
\hline Model & Experiment & Forcing & $\begin{array}{r}\text { Ensemble } \\
\text { members }\end{array}$ & $\begin{array}{r}\text { Model } \\
\text { years }\end{array}$ \\
\hline CCSM3 & Ctr11990 & Perpetual 1990 AD conditions & 1 & 400 years \\
CCSM3 & Ctr11500 & Perpetual 1500 AD conditions & 1 & 600 years \\
CCSM3 & Ctr11000 & Perpetual 1000 AD conditions & 1 & 1200 years \\
CCSM3 & TR1a-TR4a & Transient forcing (see Fig. 1) 1500-2098 AD* & 4 & 598 years \\
CCSM3 & TR1b & Transient forcing (see Fig. 1) 1000-2098 AD* & 1 & 1098 years \\
ECHO-G & Ctr11990 & Perpetual 1990 AD conditions & 1 & 1000 years \\
ECHO-G & Erik I/II & Transient forcing (see Fig. 1) 1000-2099 AD* & 2 & 1099 years \\
\hline
\end{tabular}

* Note that the transient simulations with CCSM3 and one simulation with ECHO-G use the A2 SRES scenarios for the future (see text for details).

are used for the analysis. Note that the reanalysis product only relies on surface pressure measurements, so there is some concern about its ability to represent mid-tropospheric climate variability and climate variability in areas and time periods where surface data are scarcely available (e.g. the Arctic or the North Pacific in the early period of the reanalysis product). Still, Brönnimann et al. (2011) showed for example that TCR shows a rather close agreement to early upper air data, such as the geopotential height at $500 \mathrm{hPa}$. Moore et al. (2013) showed that TCR is able to realistically represent the surface climate variability in the North Atlantic region.

Besides the reanalysis product, the study is based on model results from two different fully coupled climate models. The first model is the Climate Community System Model, Version 3 (CCSM3) developed by NCAR (Collins et al., 2006), and consists of four components: atmosphere, ocean, land surface, and sea ice, all coupled without flux adjustments. To generate ensemble simulations the lowest resolution setting is selected. The atmospheric component has $26 \sigma$-pressure levels and a horizontal resolution of T31. The land surface shares the same horizontal resolution as the atmosphere. The ocean component has 25 unevenly spaced depth levels and a nominal horizontal resolution of $3^{\circ}$ (refined around Greenland and near the Equator to approximately $0.9^{\circ}$ ). The thermodynamic and dynamic sea ice component has the same horizontal resolution as the ocean component. To assess the role of the resolution, a horizontal resolution of T85 in the atmosphere and nominal $1^{\circ}$ in the ocean is used for one simulation.

The second model (denoted as ECHO-G in the following) consists of four model components coupled, however, with an annual mean flux correction scheme for heat and freshwater (Legutke and Voss, 1999) that averages out globally. The atmospheric component is the fourth version of the European Centre model of Hamburg (ECHAM4) with a horizontal resolution of T30 and 19 $\sigma$-pressure levels (Roeckner et al., 1996). The ocean component is the Hamburg ocean model in primitive equations (HOPE) with a horizontal resolution of $2.8^{\circ} \times 2.8^{\circ}$ and 20 unevenly spaced vertical depth levels
(Wolff et al., 1997). Moreover, a land surface and a thermodynamic sea ice component are part of the model system.

Both models are used to perform (i) control simulations (Ctrl) with constant external forcing, and (ii) transient simulations (TR1a-TR4a and TR1b with CCSM3; Erik I and II with ECHO-G) with time-varying external forcing as boundary conditions (Table 1). As control simulations, four simulations with CCSM3 are available with perpetual 1000, 1500, and 1990 AD forcing. Details of the climatology and biases of the 1990 AD simulation in T31 can be found in Yeager et al. (2006). Additionally, a Ctrl simulation for 1990 AD conditions with a horizontal resolution of T85 is used to show the influence of the resolution on the results.This simulation is provided by NCAR. The Ctrl1000 and Ctrl1500 simulations are discussed in Yoshimori et al. (2010) and Hofer et al. (2011). For ECHO-G, a Ctrl1900 simulation is used. Its climatology is presented in Legutke and Voss (1999) and the variability of the Northern Hemisphere large-scale atmospheric circulation is investigated by Raible et al. (2001, 2004, 2005), Zorita et al. (2003), and Luksch et al. (2005).

Five transient simulations with CCSM3 are used, covering the last five centuries up to the last millennium. An ensemble of four simulations (TRa1 to TRa4) is integrated from 1500 to $2000 \mathrm{AD}$, where the initial states are obtained from different years of the Ctrl1500 simulation. One simulation (TRb1) spans the entire millennium, with an initial state from the Ctrl1000 simulation. For all five simulations, the same external forcing is applied, that is, greenhouse gas (GHG) concentrations, volcanic aerosols (in the stratosphere), and total solar irradiance (summarised in Fig. 1 - black lines). Further details of the simulations and the forcing functions are presented in Yoshimori et al. (2010), Hofer et al. (2011) and Lehner et al. (2012a, b). All simulations are extended to 2099 AD using the SRES A2 scenario (IPCC, 2001, 2007).

Two ECHO-G transient simulations are used, one with rather warm initial conditions (Erik I) and one with comparatively colder initial conditions (Erik II). The external forcing is slightly different from the CCSM3 simulation (Fig. 1). The greenhouse gas forcing of the transient ECHO-G simulations 

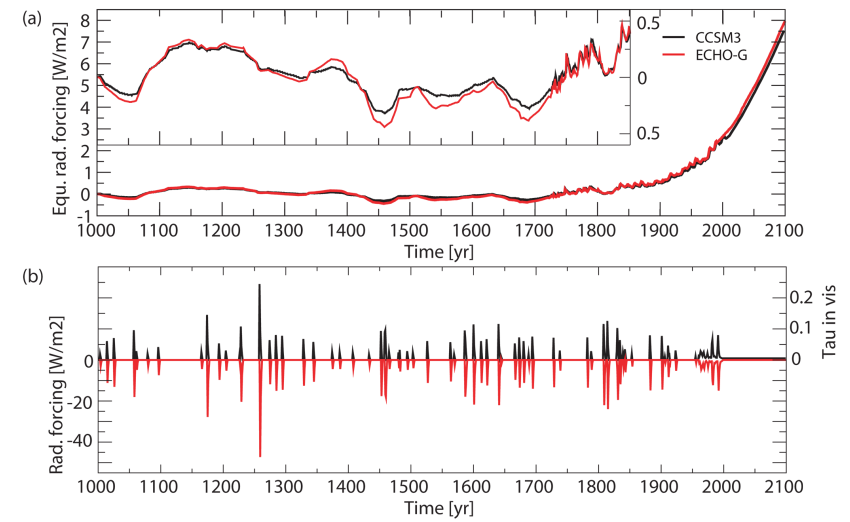

Fig. 1. Forcing from 1000 to $2100 \mathrm{AD}$ for the CCSM3 (black) and the ECHO-G (red) transient simulations: (a) solar and equivalent $\mathrm{CO}_{2}$ forcing (including $\mathrm{CO}_{2}, \mathrm{CH}_{4}$, and $\mathrm{N}_{2} \mathrm{O}$ ) with respect to mean of the period 1500-1899, and (b) the forcing representing volcanic eruptions. The forcing in (a) is represented after conversion to the equivalent radiative forcing, assuming a planetary albedo of 0.31 and using the simplified formula given in IPCC (2001, Table 6.2). The inset in (a) focuses on the forcing functions from 1000 to $1850 \mathrm{AD}$. In (b) the optical depth in the visible band represents the volcanic forcing of the CCSM3 simulations, whereas in ECHO-G the volcanic forcing is just implemented by changes of the solar constant.

is based on older reconstructions for $\mathrm{CH}_{4}$ and $\mathrm{N}_{2} \mathrm{O}$ and a different spline techniques is used for the same $\mathrm{CO}_{2}$ data. Details on these differences are discussed in Fernández-Donado et al. (2013). The volcanic forcing is only included as total solar irradiance changes; thus it only takes the direct shortwave effect of volcanic eruptions into account. As in the case of CCSM3 simulations, one simulation is extended to 2100 AD using the A2 SRES scenario. Details of these simulations are presented by González-Rouco et al. (2003, 2006, 2009) and Zorita et al. (2005). The simulations of both model setups are also compared with reconstructions and other simulations of the last millennium by assessing the temperature response to the external forcing in Fernández-Donado et al. (2013). Note that the variability of the solar forcing used to drive the CCSM3 and ECHO-G simulations is rather large, that is, total solar irradiance changes between the Late Maunder Minimum (1680-1715 AD) and the late 20th century are $0.23 \%$ (CCSM3) and $0.29 \%$ (ECHO-G), as presented in the multi-model comparison by Fernández-Donado et al. (2013).

\section{Northern Hemisphere teleconnection patterns}

In this section teleconnection patterns of the Northern Hemisphere are investigated. Therefore, we first compare the longterm mean behaviour of the model simulations with observations, wherewith the classical teleconnection patterns are introduced and model biases in the correlation patterns are discussed. The teleconnections are analysed by teleconnectivity maps based on $500 \mathrm{hPa}$ geopotential height (hereafter Z500) for winter months December to February (DJF), as first introduced by Wallace and Gutzler (1981). The teleconnectivity is a field of anti-correlation based on the geopotential height in $500 \mathrm{hPa}$. Correlating one grid point with all others, the strongest negative correlation is searched for and denoted at this grid point. Assessing all grid points by this procedure leads to a field of negative correlation where the areas of stronger negative correlation correspond to centres of action of teleconnection patterns. These centres of action are combined by teleconnection axes (Wallace and Gutzler, 1981; Raible et al., 2006). These axes are identified using a one-point correlation technique, in other words, correlating a centre of action with the Z500 field and searching for the point which delivered the strongest negative correlation. The method is applied to monthly DJF data. Prior to the application of the teleconnectivity method the seasonal cycle is removed and the data is detrended. In the second part of this section the time-varying behaviour of the correlation patterns is presented.

\subsection{Long-term mean}

Applying the method of Wallace and Gutzler (1981) to the Z500 fields of the TCR data shows the well-known teleconnection patterns for the current observational period from 1971-2000 AD (Fig. 2a). Teleconnectivity regions corresponding to the North Atlantic Oscillation (NAO) pattern, the West Pacific (WP) pattern, the Pacific North America (PNA) pattern, an area over Siberia and one connecting the eastern Mediterranean with central Europe are identified. The latter shows weaker anti-correlations than for the aforementioned regions. The teleconnections based on the entire period from 1871 to $2008 \mathrm{AD}$ show a slight reduction of the anti-correlations (Fig. 2b). This reduction is particularly observed in the North Atlantic. More importantly, the teleconnection patterns change in such a way that the more eastern position of the centres of action of the NAO during the period 1971-2000 AD (Fig. 2a) is shifted to the central Atlantic (Fig. 2b).

The simulated NAO-type teleconnection patterns substantially deviate from the observed one. In the CCSM3 Ctrl experiment, the main teleconnection pattern is shifted southwards with centres of action located south of the British Islands and south of the Canary Islands and North Africa (Fig. 2c). In the western part of the North Atlantic, CCSM3 displays a weaker NAO-type pattern. The ECHOG Ctrl experiment shows a similar southward displacement as CCSM3, omitting however a centre over North Africa. A pattern in the western part of the North Atlantic is not identified, but the Ctrl simulation shows the pattern connecting central Europe with the eastern Mediterranean region as in the observations. The simulated teleconnectivity maps of the control experiments agree with the observed pattern of the full period (1871-2008) and the recent period 1971-2000 

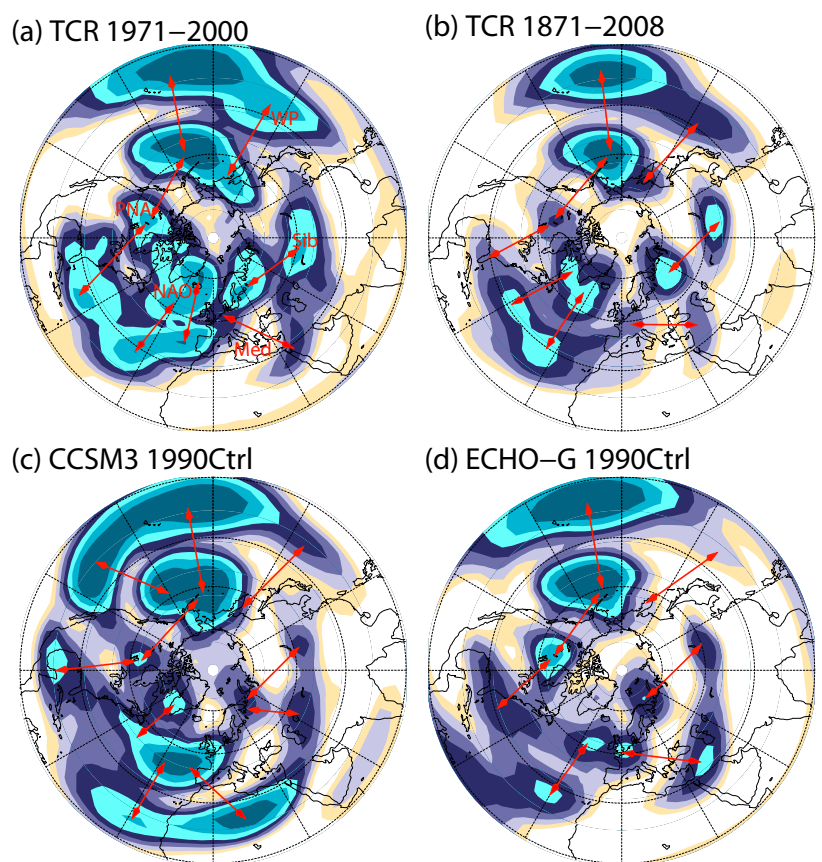

(e) CCSM3 TR01

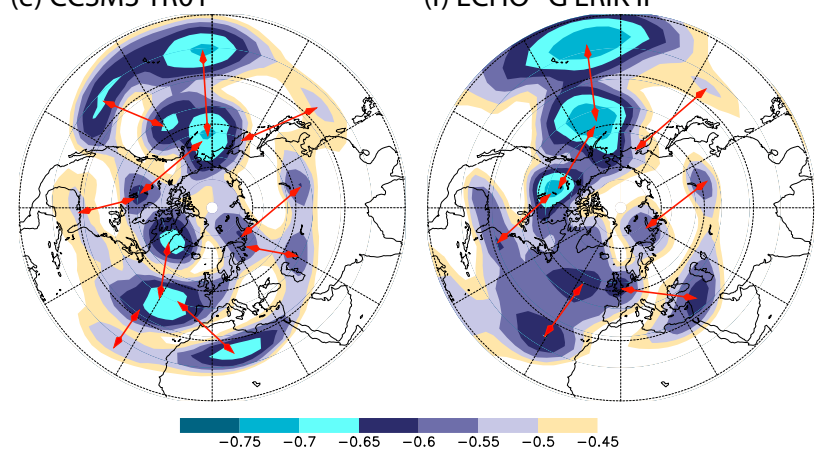

Fig. 2. Teleconnectivity based on the $500 \mathrm{hPa}$ geopotential height: (a) TCR for the reference period 1971-2000, (b) TCR for the period 1871-2008, (c) Ctrl1990 of CCSM3, (d) Ctrl1990 of ECHO-G, (e) TR1a, and (f) Erik II. Note that other simulations TR2a-TR4a and TR1b show a similar pattern as (e) and Erik I resembles the pattern of (f), therefore they are not shown. The arrows illustrate teleconnection axes and are estimated by one-point correlations in each of the centres of action, as suggested by Wallace and Gutzler (1981) and Raible et al. (2006). They show NAO-type, PNA-type, and WP-type patterns as well as a pattern over Siberia (Sib) and a pattern connecting the eastern Mediterranean with central Europe (Med) as denoted in (a).

(Fig. 2c, d) over the Pacific and Siberia. The WP and the PNA patterns are nicely represented in all Ctrl experiments with some minor deviations in CCSM3, which simulates a northsouth dipole structure in the eastern part of the Pacific and a slight westward shift of the Florida centre of the PNA pattern. The ECHO-G Ctrl experiment slightly underestimates the anti-correlation of the WP pattern.
The transient experiments of each model configuration resemble the biases of the Ctrl experiments, and their strengths of anti-correlation generally become much weaker. Thus, the model simulations exhibit in some areas substantial biases in the correlation patterns and may only be partly able to correctly simulate teleconnection patterns.

\subsection{Time behaviour of teleconnection patterns}

Differences in teleconnectivity between the entire TCR and the period from 1971-2000 AD already hint at a potential change in the strength and spatial pattern of correlations structures. To investigate the time dependence of the teleconnection patterns on decadal to multi-decadal timescales, the teleconnectivity based on Z500 is deduced using a 30year running window. The agreement or disagreement with the current observed patterns is measured by pattern correlation between the patterns of the reference period (1971$2000 \mathrm{AD}$ ) and patterns based on the running 30-year window. The pattern correlation index is derived for two areas: the North Atlantic European region $\left(100^{\circ} \mathrm{W}-50^{\circ} \mathrm{E}, 0\right.$ $\left.90^{\circ} \mathrm{N}\right)$ and the North Pacific America region $\left(230^{\circ} \mathrm{W}-70^{\circ} \mathrm{W}\right.$, $0-90^{\circ} \mathrm{N}$ ). A pattern correlation index of $r=1$ means that the teleconnection map of, e.g. a past 30-year period, perfectly matches with the current reference teleconnection map. The pattern correlation is a very demanding measure, as tests in the model world and the reanalysis show. Shifting a teleconnection pattern by, e.g. two grid points, will cause the correlation pattern to deteriorate from $r=1$ to roughly $r=0.85$. Moreover, one could test whether a pattern correlation is significant or not. In doing so we find that the pattern correlation is statistically significant at the $1 \%$ level when the correlation coefficient $r$ is greater than 0.53 for the Atlantic and $r>0.65$ for the Pacific (note that the difference is due to the high autocorrelation which deteriorates the degrees of freedom to roughly 19 for the Atlantic and 12 for the Pacific). Thus, we consider the resulting time series of pattern correlation to give evidence of periods of agreement with the current state for significant positive pattern correlation or disagreement for low or even negative pattern correlation, but we do not expect to reach $r=1$.

The pattern correlation index time series of TCR shows disagreement with the reference teleconnection patterns already in the 20th century for the North Atlantic region (Fig. 3a). In the period from 1940-1969 AD the pattern correlation $r$ is below 0.5 . This is a hint that the correlation structure experiences a substantial change during this time. Going further back in time, the agreement of the teleconnection patterns with the reference pattern increases to levels of 0.6 to 0.7 in TCR. The data quality and amount is reduced in the early part of this reanalysis product and may affect the ensemble mean. To test this, each ensemble member of the reanalysis is investigated separately. The results for individual ensemble members agree well among each other and confirm the robustness of the anomalous period from 1940-1969 AD. 
(a) TCR

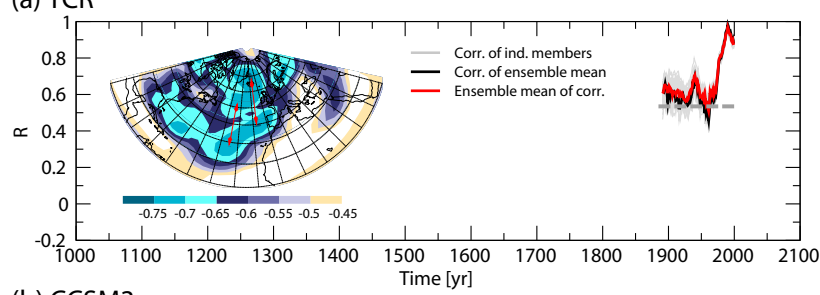

(b) CCSM3

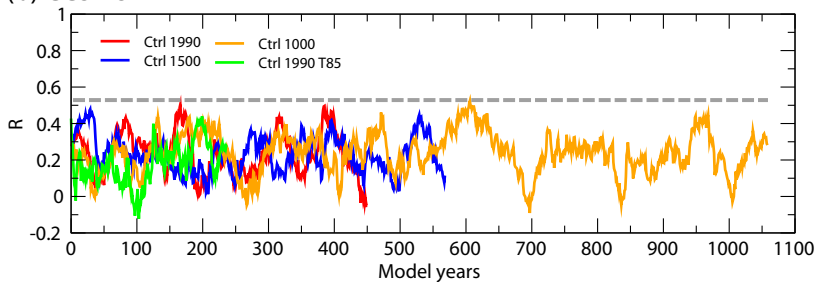

(c) ECHO-G

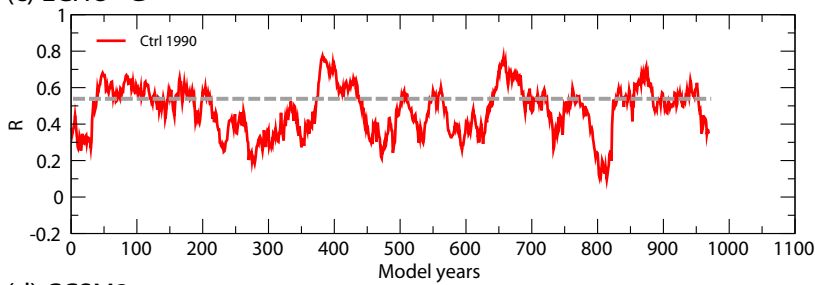

(d) CCSM3

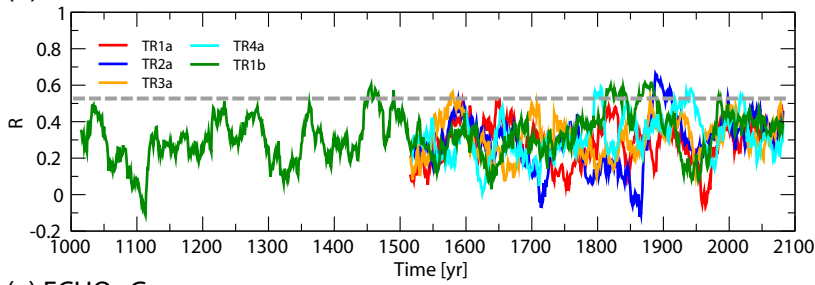

(e) ECHO-G

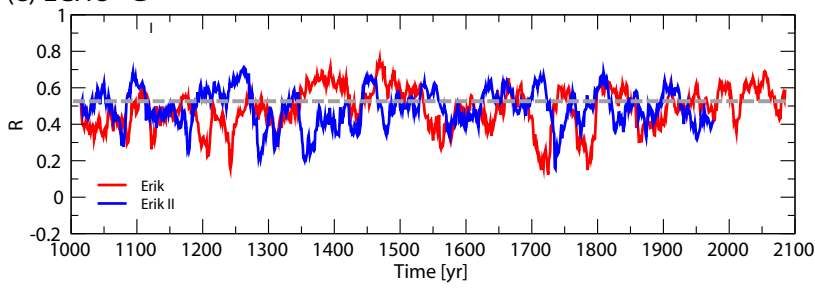

Fig. 3. Running spatial correlation time series using a 30-year window and the reference teleconnectivity pattern (inset in a) for the Atlantic: (a) TCR 1871 to 2010, (b) CCSM3 Ctrl simulations, (c) Ctr11990 of ECHO-G, (d) transient simulations with CCSM3, and (e) transient simulations with ECHO-G. In (a) the black time series shows the running spatial correlations using the ensemble mean TCR data; the grey time series are the running spatial correlations for each individual member of TCR and in red the mean of the grey time series is presented. The $1 \%$ significance level of the pattern correlation is illustrated by the grey dashed line.

Moreover, the mean over all the ensemble members is similar to the correlation time series derived from the ensemble mean field which illustrates that TCR is rather well constrained in the North Atlantic.

The climate model simulations show a different picture (Fig. 3b-e). Overall the pattern correlation is reduced, which hints that the climate model simulations may have deficiencies in their simulation of the teleconnection patterns as mentioned previously. Still, there are also differences between the models. CCSM3 shows a pattern correlation range of approximately -0.2 to 0.7 (with a mean of 0.2 ), whereas ECHO-G has a range of roughly 0 to 0.8 (mean of 0.4 ). This indicates that the model biases in CCSM3 are stronger than in ECHO-G relative to the 1971-2000 baseline. Moreover, increasing the resolution to T85 shows no substantial difference for the CCSM3 model family. Despite these biases, all simulations show decadal-scale variability of periods with agreement $(r>0.6)$ and disagreement (low or negative $r$ ). Comparing the $\mathrm{Ctrl}$ simulations with the corresponding transient simulations we find no difference in the range of pattern correlation, nor a difference in the variability of the time series. Moreover, the variability of the pattern correlation indices of the transient simulations shows no coherence among each other and is unrelated to changes in the external forcing for both models (Fig. 1). This holds true for the future as well when no systematic response to the increased forcing from greenhouse gases is detectable. Also, the mean climate state seems to be irrelevant for the variability of agreement as illustrated for the CCSM3 model by the different Ctrl simulations. None of these simulations show a substantial difference with respect to periods of agreement and disagreement.

For the Pacific region, the TCR teleconnection patterns show a decrease in agreement with the reference pattern when going back in time (Fig. 4a). The lowest values of the pattern correlation index are identified at the beginning of TCR during the period 1871 to 1900 AD. Analysing the ensemble members separately shows that the time series based on the ensemble mean of TCR exceeds the range given by the ensemble members. This is a hint that this reanalysis product is not well constrained by observations in the Pacific during the early period, and thus the results for this period are not trustworthy and could overemphasise the disagreement. Focusing on the period 1915-2010 AD, where the reanalysis is better constrained by observations (nearly no difference between the mean over all the ensemble members and the correlation time series derived from the ensemble mean field), the pattern correlations show some change from 1 to roughly 0.7 . This range is smaller compared to the North Atlantic, suggesting that more stable and time-independent teleconnection patterns are active in the Pacific than in the Atlantic. The model simulations support this result, showing a reduced range of the corresponding pattern correlation indices for the Pacific (Fig. 4b-e). As for the Atlantic, the simulations show biases for the Pacific relative to the 19712000 baseline. No pattern correlation close to 1 is identified, in other words, no time period resembles the current observations 1971-2000 AD in a perfect manner. The mean pattern correlation is reduced to $\sim 0.4$ for $\mathrm{CCSM} 3$ and $\sim 0.6$ for ECHO-G. Again, using a higher resolution in CCSM3 shows no substantial improvement in simulating the teleconnections compared with the T31 control simulations. Further, the time 
(a) TCR

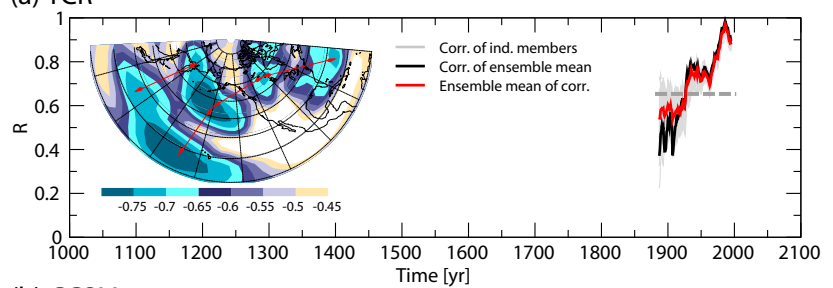

(b) CCSM3

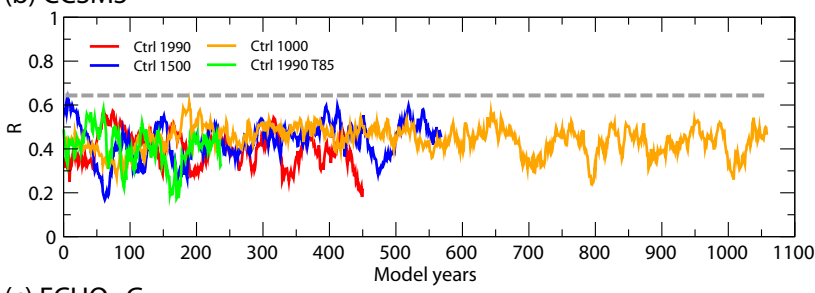

(c) ECHO-G

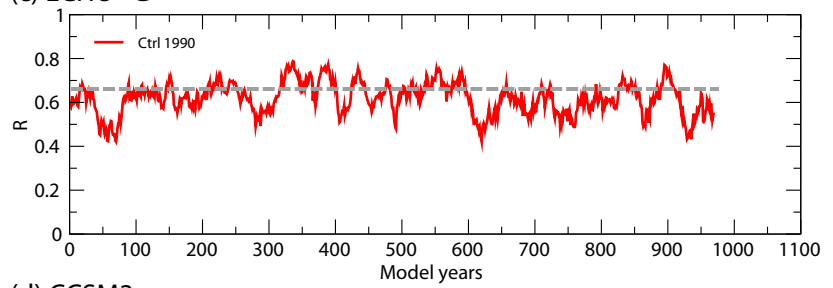

(d) $\mathrm{CCSM} 3$

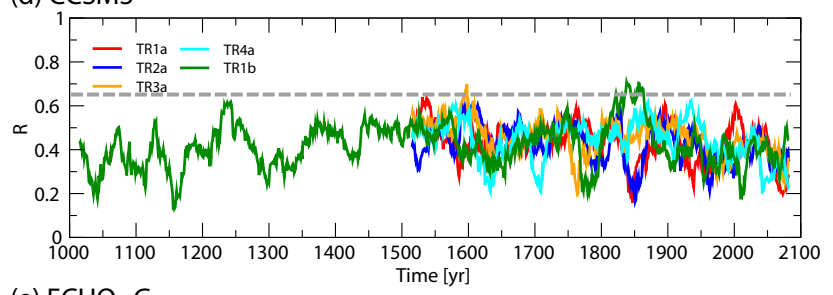

(e) ECHO-G

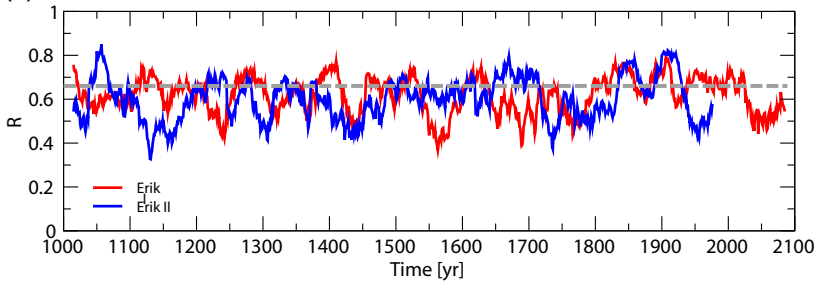

Fig. 4. As Fig. 3, but for the Pacific (see inset in a).

series of the Pacific behave similarly in the Ctrl and transient simulations and no external forcing imprint (or under future GHG forcing) is found.

Thus, we conclude that the temporal variability of simulated teleconnections of the Northern Hemisphere north of $20^{\circ} \mathrm{N}$ is not different from internal climate variability for the last 1000 years. Moreover, the results are not sensitive to the window size (not shown).

\subsection{Spatial differences of teleconnection patterns}

Further insights in the differences of the correlation patterns are gained by a composite analysis of the 30 -year running window teleconnectivity patterns. Therefore, the time series of pattern correlation are used as an index. If this index exceeds two standard deviations, the corresponding teleconnectivity maps are selected and averaged in order to obtain the mean teleconnectivity map, which shows the closest agreement with the 1971-2000 baseline. If the index is below two standard deviations, the mean teleconnectivity map illustrates the pattern, which disagrees with the reference pattern of 1971-2000. These composites illustrate the characteristic teleconnection patterns of agreement and disagreement with the reference pattern. It shall be mentioned that the mean of different teleconnectivity patterns is not necessarily meaningful. However, in the analysis presented below the composite spans a similar range of correlation coefficients from -0.75 to -0.45 as the teleconnectivity deduced from a single 30-year period, e.g. 1971-2000. This indicates that the patterns included in the composites are very similar to each other. Therefore the application of a composite analysis is trustworthy. As increasing the resolution of CCSM3 shows no difference, the T85 simulation is excluded from this analysis.

The composite of the high pattern correlation index in the North Atlantic resembles the observed reference pattern as expected in reanalysis and models (Fig. 5, left column). Moreover, the range of the teleconnectivity of the composites is similar to the observed reference period and indicates that the variability between the composite members is low and the identified patterns are therefore a robust description of the correlation pattern for high index conditions. All model simulations show the well-known dipole pattern of the NAO. Again, CCSM3 shows some stronger deviations when comparing Fig. 5c, g with observations (Fig. 5a), where a pattern connecting North Africa with a centre located north of Spain is identified in the simulations. This explains the lower maximum pattern correlation found for CCSM3. The ECHOG simulations agree better than CCSM3, but still overemphasise the teleconnectivity in central Europe, which is connected with the eastern Mediterranean (Fig. 5e, i). Concerning situations of disagreement in the TCR (the period 19401969 AD) the NAO-type teleconnection is shifted to the west and a new wave-train-like teleconnection pattern connecting the British Islands with West Greenland and the eastern Mediterranean is detected (Fig. 5b). The simulated composites of the low pattern correlation index in the North Atlantic partly resemble the observed patterns (Fig. 5d, f, h, j). CCSM3 simulates the western shift of the NAO-type pattern, however the southern centre of this western pattern is shifted northwards with respect to Fig. 5b. Moreover, CCSM3 does not show the pattern over Europe. Instead, the model shows the tripole pattern with centres of action located south of the British Islands and south of the Canary Islands and North Africa already discussed in Sect. 3.1 as model bias. In contrast, the ECHO-G simulations identifies the Europeaneastern Mediterranean pattern, however they fail to generate the western shift of the NAO-type pattern. Instead the 


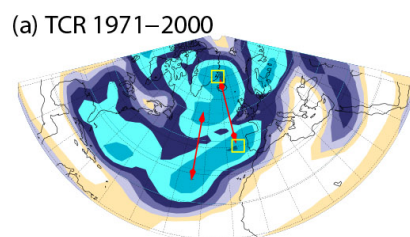

(c) $\operatorname{CCSM} 3 \mathrm{Ctrl}$

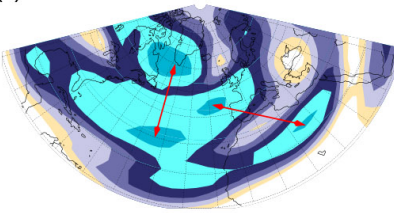

(e) ECHO-G Ctrl

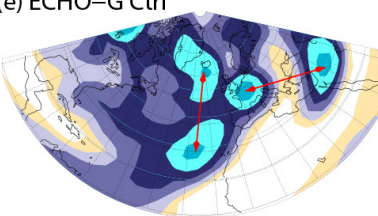

(g) CCSM3 transient

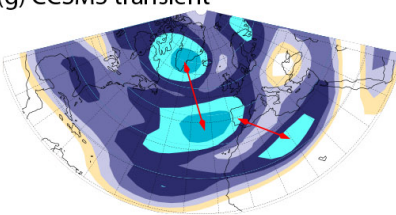

(i) ECHO-G transient

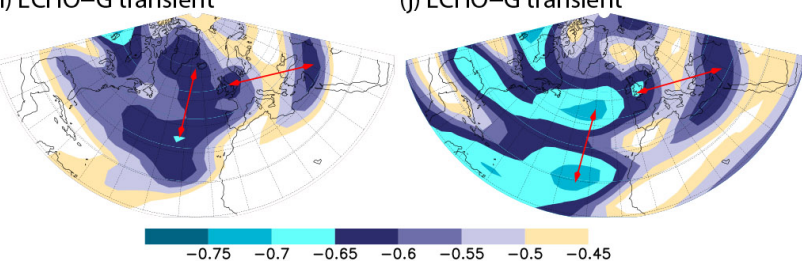

Fig. 5. Composites of teleconnectivity for all periods with high (left panels) and low (right panels) spatial correlation in the Atlantic: (a) TCR for period 1971-2000, (b) TCR for period 1940-1969, (c, d) composites of all CCSM3 Ctrl simulations, (e, f) composites of the ECHO-G Ctrl1990 simulation, (g, h) composites of all CCSM3 transient simulations and $(\mathbf{i}, \mathbf{j})$ composites of all ECHO-G transient simulations. Note that the composites are selected according to a distance of at least two standard deviations from the mean of the corresponding spatial correlation times series of Fig. 3. The yellow squares in (a) and (b) show the location for the index definition in Sect. 4.

NAO-type pattern is shifted southwards by roughly $10^{\circ}$, reflecting the biases of ECHO-G (Sect. 3.1).

The North Pacific composite of the high pattern correlation index resembles the observed reference pattern from 19712000 AD (Fig. 6, left column). The WP and PNA patterns are found in all simulations with only minor deviations in the locations of the centres of action (i.e. the composite of CCSM3 shows a tendency to split the tropical centre of the PNA pattern into two; Fig. 6c). Again, this is expected, as the pattern correlation indices are on average higher than for the Atlantic (Figs. 3 and 4). The observed anomalous period is from 1915 to $1944 \mathrm{AD}$, where the lowest pattern correlation is found for the reliable period 1915-2008 (Fig. 4a). The corresponding teleconnectivity (Fig. 6b) exhibits a change in the PNA pattern, shifting its centres of action over southwest Canada and over Florida to the Gulf of Mexico. Moreover, the WP pattern is shifted to the northwest. Concerning the model simulations for the anomalous patterns, we find that the PNA pattern is only weakly affected with a slight shift of the Florida centre of action. The main difference is found in the western part of the Pacific where the model simulations lose the WP pattern. Additionally, CCSM3 simulates a split of the tropical centre of the PNA, which is potentially a model bias (Sect. 3.1). As for the Atlantic, the Pacific composites of the model simulations show a similar range of teleconnectivity as the observations, therefore giving evidence of the robustness of these patterns. Overall, the changes in the North Pacific are less pronounced than in the Atlantic, favouring the conclusion that teleconnections in the Pacific are more stable than in the Atlantic.

\section{Implications for proxy reconstructions}

Proxy-based reconstructions for past atmospheric circulation patterns rely, as mentioned before, on the assumption of stationarity in the relationship between a proxy signal and the corresponding atmospheric circulation. It has been illustrated in a number of studies that this assumption, primarily derived from late TCR, might not hold if one considers longer timescales (e.g. Lehner et al., 2012b). Moreover, within the observational period as well as in model simulations, the teleconnection patterns in both the Atlantic and Pacific change over time (as demonstrated in Sect. 3). This means that what are currently (1971-2000 AD) considered the dominant teleconnection patterns (e.g. NAO and PNA) do not necessarily look the same during other time periods of equal length. Therefore one can expect that, along with changes in the teleconnection patterns, the correlation strength of a fixed proxy site with the atmospheric circulation may change.

The period of maximum disagreement with the reference teleconnectivity pattern in the Atlantic in TCR (19401969 AD) features the NAO-like dipole, but substantially shifted to the west (Fig. 5b). This pattern is termed the Baffin Island-West Atlantic (BWA) pattern (Shabbar et al., 1997) and is defined here from the maxima of teleconnectivity in the North Atlantic during this time period:

$\mathrm{BWA}=0.5 \cdot\left[Z^{\prime}\left(39^{\circ} \mathrm{N} ; 62^{\circ} \mathrm{W}\right)-Z^{\prime}\left(68^{\circ} \mathrm{N} ; 64^{\circ} \mathrm{W}\right)\right]$,

with $Z^{\prime}$ being the normalised $Z 500$ time series. The degree of independence of the BWA from the NAO has been discussed (e.g. Shabbar et al., 1997) and new studies describe a distinct anti-phasing of BWA and NAO during certain periods of the twentieth century (e.g. Moore et al., 2011)

Similarly, an index is defined for the wave train that emerges in the eastern North Atlantic region (hereafter AWAVE) during the anomalous period of 1940-1969 AD: 


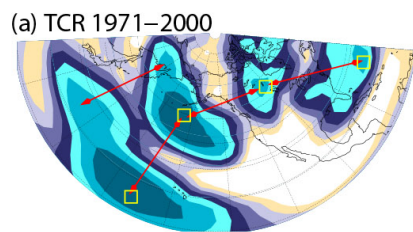

(c) $\operatorname{CCSM} 3 \mathrm{Ctrl}$

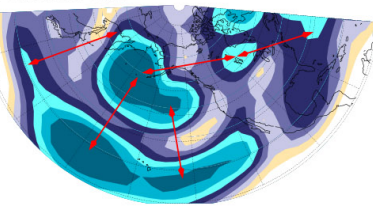

(e) ECHO-G Ctrl

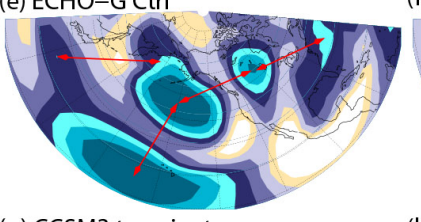

(g) CCSM3 transient

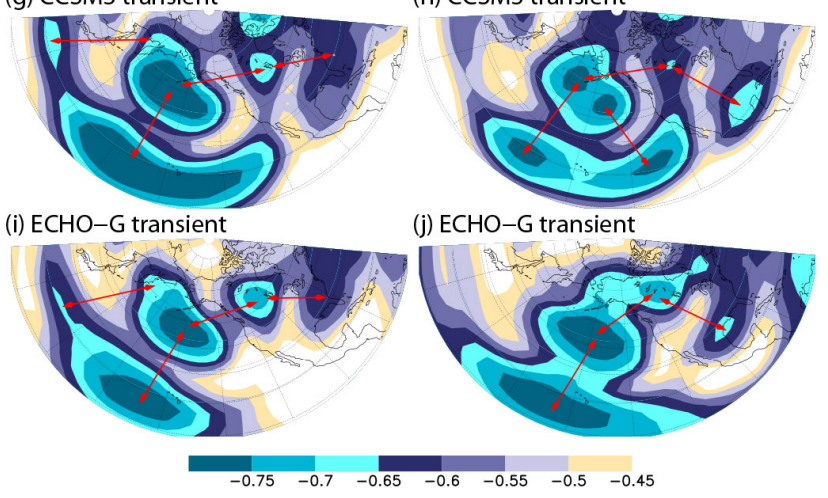

Fig. 6. Composites of teleconnectivity for all periods with high (left panels) and low (right panels) spatial correlation in the Pacific: (a) TCR for period 1971-2000, (b) TCR for period 1915-1944, (c, d) composites of all CCSM3 Ctrl simulations, $(\mathbf{e}, \mathbf{f})$ composites of the ECHO-G Ctrl1990 simulation, (g, h) composites of all CCSM3 transient simulations and (i, $\mathbf{j})$ composites of all ECHO-G transient simulations. Note that the composites are selected according to a distance of at least two standard deviations from the mean of the corresponding spatial correlation times series of Fig. 4. The yellow squares in (a) and (b) show the location for the index definition in Sect. 4.

$$
\begin{gathered}
\text { AWAVE }=0.5 \cdot Z^{\prime}\left(50^{\circ} \mathrm{N} ; 7^{\circ} \mathrm{E}\right)-0.25 \cdot\left[Z ^ { \prime } \left(32^{\circ} \mathrm{N} ;\right.\right. \\
\left.\left.37^{\circ} \mathrm{E}\right)+Z^{\prime}\left(80^{\circ} \mathrm{N} ; 29^{\circ} \mathrm{W}\right)\right] .
\end{gathered}
$$

AWAVE bears similarities with the North Sea-Caspian Pattern (NCP; Kutiel and Benaroch, 2002), however, it features a third node at higher latitudes and has the eastern node shifted south compared to NCP.

The usefulness of these two indices, BWA and AWAVE, in describing climate variability over time can now be tested and compared against the NAO. Figure 7 shows the coefficient of determination $R^{2}$ (the squared correlation of an index with a climate field, serving as an estimate of explained variance) of the indices NAO, BWA, and AWAVE for the classical proxy variables of precipitation and surface air temperature (SAT) during the phase of strong and weak NAO-like teleconnection (1971-2000 and 1940-1969, respectively). Additionally, $R^{2}$ is also shown for sea level pressure (SLP). As known from earlier studies (e.g. Hurrell, 1995), the NAO describes variability of precipitation in the western Mediterranean region and northern Europe, SAT in central Europe and Greenland, and the SLP dipole between Iceland and the Azores. Compared to the NAO, the BWA shows smaller coefficients for precipitation, but larger coefficients for SAT in the western part of the North Atlantic. Similar to the NAO it has an equivalent barotropic signature in the SLP. The AWAVE explains a substantial amount of precipitation and SAT variability mainly over Europe. It is interesting to see that the AWAVE has no equivalent barotropic imprint in SLP, but features a SLP dipole with a southern node centred on Europe.

By averaging $R^{2}$ across the North Atlantic domain and - more important for proxies - the continental Atlantic domain, the time evolution of the coefficient of determination is illustrated (Fig. 8). The NAO describes North Atlanticwide climate variability best during roughly the last 30 40 years, when it profits from high values in selected areas, expressed as a large area fraction of values exceeding 0.4 $(0.4=40 \%$ variability explained, which is a good estimate for mode dominance). Before that, the spatially averaged $R^{2}$ of NAO drops and BWA or AWAVE usually show higher index values.

This becomes even more apparent when considering only the land area, where the AWAVE describes a larger fraction of the climate variability than the NAO for most of the time. Except for the period around 1920, when none of the indices shows particularly high values, the AWAVE displays higher or equally high values as the NAO in both spatial average and area fraction $>0.4$ of $R^{2}$. The BWA index shows good spatially averaged coefficients, but covers only a small area with values $>0.4$.

As mentioned in the previous section, changes are much weaker for the PNA. The PNA during 1971-2000 and its shifted expression during the period of largest disagreement, 1915-1944, are defined as

$$
\begin{aligned}
\mathrm{PNA} & =0.25 \cdot\left[Z\left(17^{\circ} \mathrm{N}, 173^{\circ} \mathrm{W}\right)-Z\left(46^{\circ} \mathrm{N}, 165^{\circ} \mathrm{W}\right)\right. \\
& \left.+Z\left(58^{\circ} \mathrm{N}, 105^{\circ} \mathrm{W}\right)-Z\left(28^{\circ} \mathrm{N}, 83^{\circ} \mathrm{W}\right)\right]
\end{aligned}
$$

and

$$
\begin{aligned}
\mathrm{PNA}_{\text {shifted }} & =0.25 \cdot\left[Z\left(19^{\circ} \mathrm{N}, 173^{\circ} \mathrm{W}\right)-Z\left(53^{\circ} \mathrm{N}, 169^{\circ} \mathrm{W}\right)\right. \\
& \left.+Z\left(45^{\circ} \mathrm{N}, 113^{\circ} \mathrm{W}\right)-Z\left(30^{\circ} \mathrm{N}, 98^{\circ} \mathrm{W}\right)\right] .
\end{aligned}
$$

The surface signatures of these two indices are largely congruent, even when comparing them in the two different periods (Fig. 9). This indicates that the PNA of the twentieth century is a relatively robust mode. Also, the spatially averaged $R^{2}$ of the two PNA expressions for temperature and precipitation are highly correlated over time (not shown). 


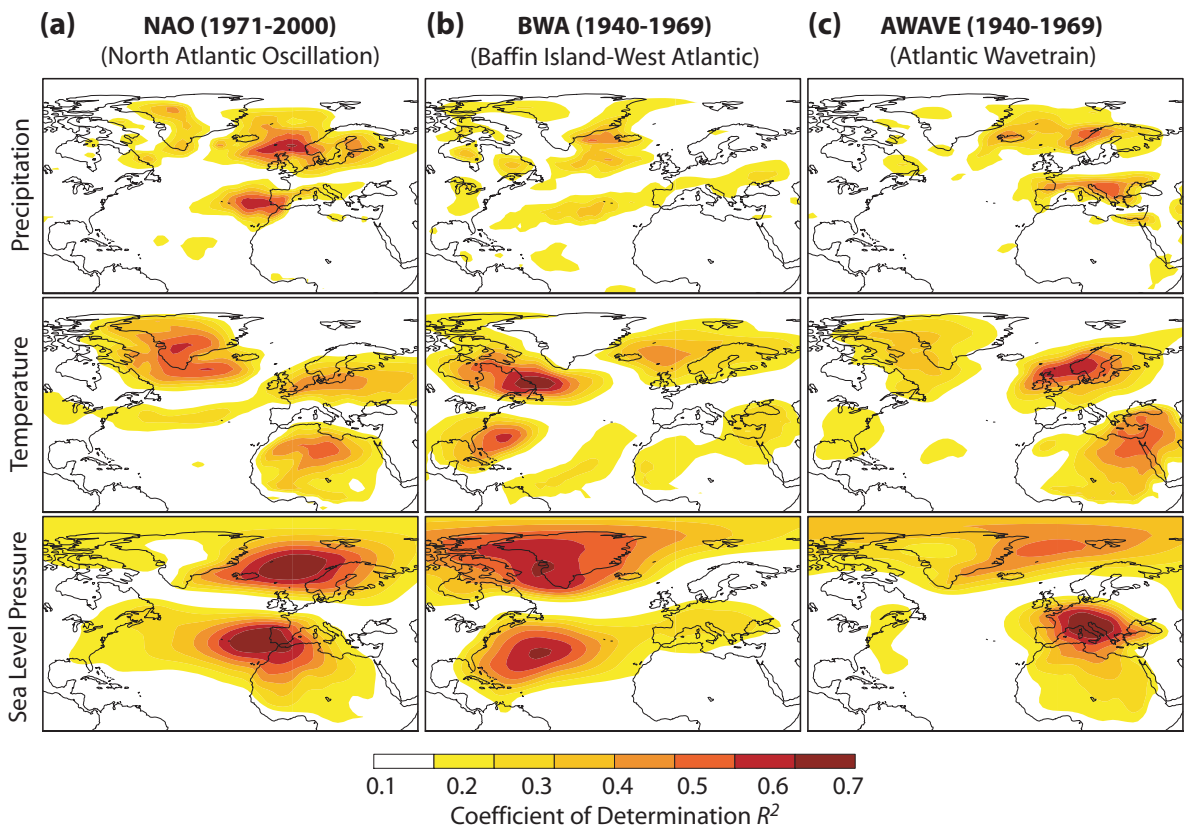

Fig. 7. Coefficient of determination of (a) the North Atlantic Oscillation (NAO), (b) the Baffin Island-West Atlantic pattern (BWA), and (c) the Atlantic Wave Train (AWAVE) for precipitation, surface air temperature, and sea level pressure, deduced from the TCR ensemble mean. The time period 1971-2000 is defined as the reference period; 1940-1969 is the 30-year period of largest disagreement in teleconnectivity from the reference period. See text for further details.

North Atlantic domain (land and ocean)
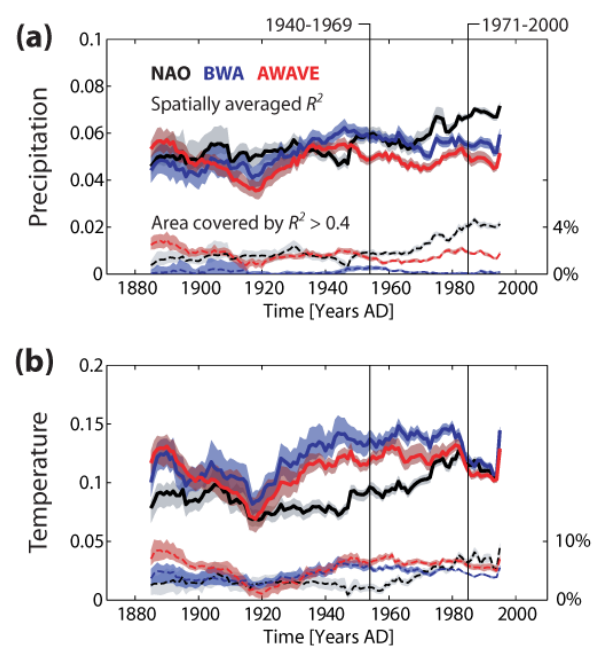

North Atlantic domain

(c)

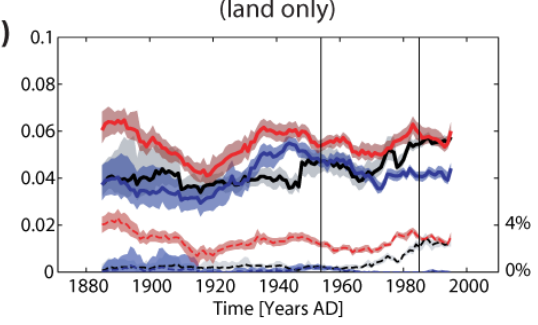

(d)

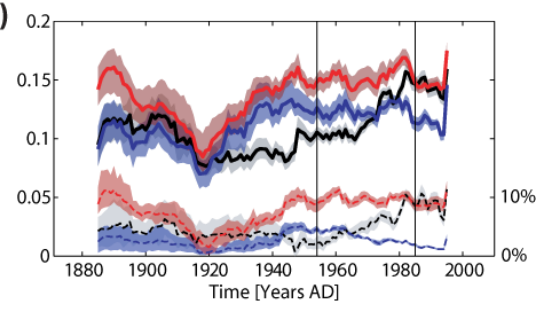

Fig. 8. Explanatory power of teleconnection modes in TCR. (a; upper lines, left $y$ axis) 30-year moving spatially averaged coefficient of determination $R^{2}$ of the NAO, BWA, and AWAVE for precipitation over the North Atlantic domain (see text and Fig. 7 for details on domain and indices). (a) lower lines, right $y$ axis) 30-year moving average of fraction of domain area where $R^{2}>0.4$. Vertical lines mark the two periods shown in Fig. 7. (b) Same as (a) but for temperature. (c, d) Same as (a, b) but for the North Atlantic land only. Shown is the range of the ensemble members and the ensemble mean of the individual members.

\section{Conclusions}

Changing correlation structures of the Northern Hemisphere atmospheric circulation are investigated for the period 1000-2100 $\mathrm{AD}$ using reanalysis data and different sets of millennium-long control and externally forced simulations with two coupled climate models. The observed and simulated centres of action of the major teleconnection patterns for NAO and PNA are not stable in time. In particular, the observed patterns in the North Atlantic sector vary strongly, 


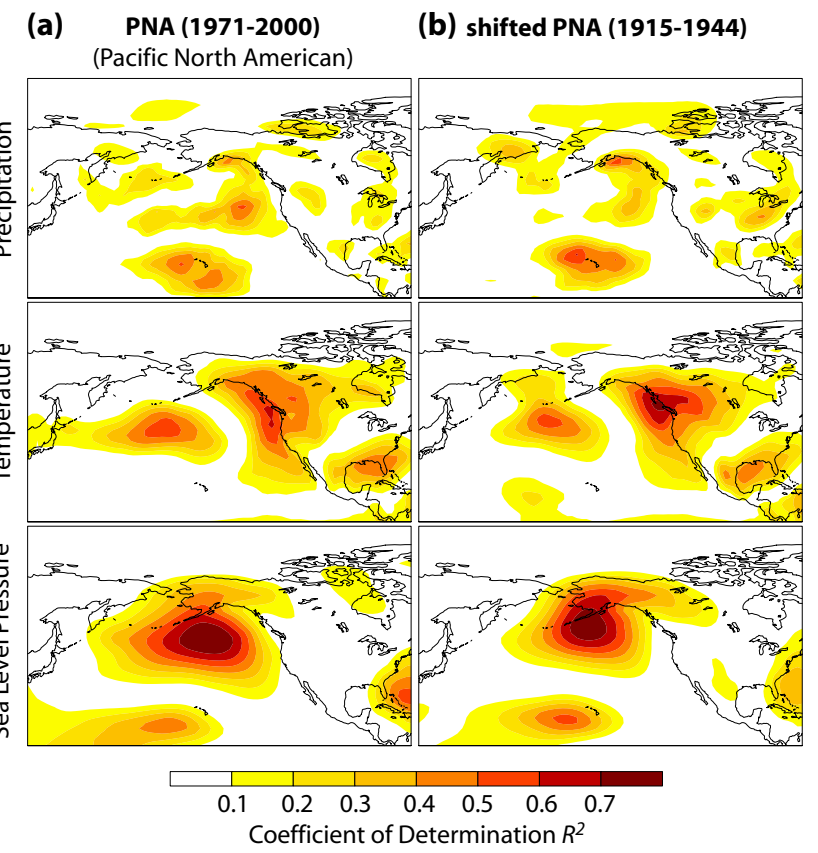

Fig. 9. As Fig. 7 but for (a) the Pacific North American pattern (PNA) and (b) the shifted PNA.

showing a splitting in a north-south dipole in the western part of the North Atlantic, and a wave train pattern in the eastern part and over Europe during some periods. The observed structural changes in the North Pacific and over North America are smaller compared to the North Atlantic. The findings for the North Atlantic are in line with earlier studies assuming a non-stationarity of the centres of action of the NAO (Raible et al., 2001, 2006), a continuum of teleconnection patterns (Franzke and Feldstein, 2005) and recently a postulated changing linear combination of the leading modes of variability in the North Atlantic (Moore et al., 2013).

Expanding the analysis further back in time and into the future with model simulations complements the picture, although model biases are evident in simulating the teleconnection patterns and the locations of their centres of action. These biases remain even when the resolution is increased, as illustrated by one model set up. This is a hint that climate models still suffer from under-representation of important atmospheric processes, such as blocking action (Woollings et al., 2010a; Buehler et al., 2011) or stratosphere-troposphere interaction (e.g. Kodera et al., 1996) and demonstrate our incomplete understanding of atmosphere dynamics. Despite these biases, the model simulations show strong variability of the teleconnection patterns over time, and to some extent similar deviations are found in the reanalysis data for the past 130 years. Comparing the transient simulations with external forcing and with the behaviour of the corresponding control simulations shows that the temporal variability of teleconnections of the Northern Hemisphere north of $20^{\circ} \mathrm{N}$ is, over time, not different from internal climate variability for the last 1000 years. Even for the rather high external forcing of the A2 scenario for the future, a systematic change is not found. This contradicts earlier findings by Ulbrich and Christoph (1999) who suggested a north-eastwards shift of the NAO centres of action under greenhouse-gas-induced warming. Whether this is a robust finding is questionable, as our ensemble of opportunity encompasses only three simulations and should be assessed in a wider pool of simulations such as CMIP5 (Taylor et al., 2012).

The reasons for changing teleconnection structures are less understood. The periods in the reanalysis where teleconnection patterns disagree with the current locations resemble, to some extent, periods with different atmosphere-ocean coupling. Raible et al. (2001) identified periods during which decadal-scale variability of the NAO coincides with strong coupling of the atmosphere to the ocean underneath, whereas periods dominated by interannual variability seem to be related to tropical SST changes in the Pacific. In line with these changes, the coupling between the Atlantic and $\mathrm{Pa}-$ cific is found to be variable over time (Raible et al., 2004; Luksch et al., 2005; Pinto et al., 2011). Other reasons such as stratosphere-troposphere interaction (Kodera et al., 1996; Woollings et al., 2010a) or sea-ice interaction with the atmosphere (e.g. Lehner et al., 2013) are also potential drivers of such changes, but this needs to be the focus of future research.

Another important conclusion concerns the reconstruction of modes of variability back in time. Such reconstructions rely on a stationary relationship between the proxy site and the atmospheric mode, often implying that the dominant atmospheric mode does not change over time. We show that changes in the dominant mode occur already in the twentieth century, in particular in the North Atlantic. The explanatory power of the NAO for climate variability, for example, is highest in the last 30-40 years. Before that, the emergence of other modes draws a more complex picture of atmospheric variability and contrasts with the simplified interpretation of atmospheric teleconnections usually presented in paleoclimate reconstructions.

Selected proxy sites may be used to reconstruct a known atmospheric mode (e.g. the NAO as we know it from 19712000), but we have no good means yet to determine whether this was actually the dominant mode. However, knowing the dominant mode is important for the interpretation of independent proxies, as different modes can imply different physical mechanisms for a recorded proxy signal. Given the popularity in the literature to relate new proxies to the dominant modes (e.g. Trouet et al., 2009; Olsen et al., 2012), it is important to develop gridded reconstructions of sea level pressure (Küttel et al., 2010) along with new methods that allow us to determine the dominant mode from a proxy network.

Together with other studies (e.g. Lehner et al., 2012b) these results offer potential explanations for discrepancies between existing reconstructions of modes of variability. 
Further, they advise future reconstructions of atmospheric modes to thoroughly test and carefully select the proxies to be used and, most importantly, to cautiously interpret their results with respect to what part of past climate variability can be explained by a specific reconstruction.

Acknowledgements. This work is supported by the Sinergia project FUPSOL funded by the Swiss National Science Foundation. 20th Century Reanalysis data is provided by the NOAA/OAR/ESRL PSD, Boulder, Colorado, USA (from their website at http://www.esrl.noaa.gov/psd/). The CCSM3 simulations are performed on the super computing architecture of the Swiss National Supercomputing Centre (CSCS). LFD and JFGR were supported by CGL 2011-29677-602-02, CGL 2011-29672-602-01, and the FPU grant AP2009-4061.

Edited by: H. Goosse

\section{References}

Barnston, A. G. and Livezey, R. E.: Classification, seasonality and persistence of low-frequency atmospheric circulation patterns, Mon. Weather Rev., 115, 1825-1850, 1987.

Brönnimann, S., Compo, G. P., Spadin, R., Allan, R., and Adam, W.: Early ship-based upper-air data and comparison with the Twentieth Century Reanalysis, Clim. Past, 7, 265-276, doi:10.5194/cp7-265-2011, 2011.

Buehler, T., Raible, C. C., and Stocker, T. F.: On the relation of extreme North Atlantic blocking frequencies, cold spells, and droughts in ERA-40 in winter, Tellus, 63, 212-222, 2011.

Casty, C., Raible, C. C., Stocker, T. F., Wanner, H., and Luterbacher, J.: European climate pattern variability since 1766, Clim. Dynam., 29, 791-805, 2007.

Collins, W. D., Bitz, C. M., Blackmon, M. L., Bonan, G. B., Bretherton, C. S., Carton, J. A., Chang, P., Doney, S. C., Hack, J. J., Henderson, T. B., Kiehl, J. T., Large, W. G., McKenna, D. S., Santer, B. D., and Smith, R. D.: The Community Climate System Model version 3 (CCSM3), J. Climate, 19, 2122-2143, 2006.

Compo, G., Whitaker, J., and Sardeshmukh, P.: Feasibility of a 100year reanalysis using only surface pressure data, B. Am. Meteorol. Soc., 87, 175-190, 2006.

Compo, G. P., Whitaker, J. S., Sardeshmukh, P. D., Matsui, N., Allan, R. J., Yin, X., Gleason Jr., B. E., Vose, R. S., Rutledge, G., Bessemoulin, P., Broennimann, S., Brunet, M., Crouthamel, R. I., Grant, A. N., Groisman, P. Y., Jones, P. D., Kruk, M. C., Kruger, A. C., Marshall, G. J., Maugeri, M., Mok, H. Y., Nordli, O., Ross, T. F., Trigo, R. M., Wang, X. L., Woodruff, S. D., and Worley, S. J.: The Twentieth Century Reanalysis Project, Q. J. Roy. Meteorol. Soc., 137, 1-28, 2011.

Cook, E. R., D’Arrigo, R. D., and Mann, M. E.: A well-verified, multiproxy reconstruction of the winter North Atlantic Oscillation index since AD 1400, J. Climate, 15, 1754-1764, 2002.

Defant, A.: Die Schwankungen der atmosphärischen Zirkulation über dem nordatlantischen Ozean im 25-jährigen Zeitraum 1881-1905, Geogr. Ann., 6, 13-41, 1924.
Fernández-Donado, L., González-Rouco, J. F., Raible, C. C., Ammann, C. M., Barriopedro, D., García-Bustamante, E., Jungclaus, J. H., Lorenz, S. J., Luterbacher, J., Phipps, S. J., Servonnat, J., Swingedouw, D., Tett, S. F. B., Wagner, S., Yiou, P., and Zorita, E.: Large-scale temperature response to external forcing in simulations and reconstructions of the last millennium, Clim. Past, 9, 393-421, doi:10.5194/cp-9-393-2013, 2013.

Franzke, C. and Feldstein, S. B.: The continuum and dynamics of Northern Hemisphere teleconnection patterns, J. Atmos. Sci., 62, 3250-3267, 2005.

González-Rouco, F., von Storch, H., and Zorita, E.: Deep soil temperature as proxy for surface air-temperature in a coupled model simulation of the last thousand years, Geophys. Res. Lett., 30, doi:10.1029/2003GL018264, 2003.

González-Rouco, J. F., Beltrami, H., Zorita, E., and von Storch, H.: Simulation and inversion of borehole temperature profiles in surrogate climates: Spatial distribution and surface coupling, Geophys. Res. Lett., 33, doi:10.1029/2005GL024693, 2006.

González-Rouco, J. F., Beltrami, H., Zorita, E., and Stevens, M. B.: Borehole climatology: a discussion based on contributions from climate modeling, Clim. Past, 5, 97-127, doi:10.5194/cp-5-972009, 2009.

Hann, J.: Zur Witterungsgeschichte von Nord-Grönland, Westküste, Meteorl. Z., 15, 787-799, 1890.

Hofer, D., Raible, C. C., and Stocker, T. F.: Variations of the Atlantic meridional overturning circulation in control and transient simulations of the last millennium, Clim. Past, 7, 133-150, doi:10.5194/cp-7-133-2011, 2011.

Hurrell, J. W.: Decadal trends in the North Atlantic Oscillation: Regional temperatures and precipitation, Science, 269, 676-679, 1995.

Hurrell, J. W. and Deser, C.: North Atlantic climate variability: The role of the North Atlantic Oscillation, J. Mar. Syst., 78, 28-41, 2009.

Hurrell, J. W., Hoerling, M. P., Phillips, A., and Xu, T.: Twentieth century North Atlantic climate change, Part I: Assessing determinism, Clim. Dynam., 23, 371-389, 2004.

IPCC: Climate Change 2001: The Scientific Basis, Contribution of Working Group I to the Third Assessment Report of the Intergovernmental Panel on Climate Change, Cambridge University Press, Cambridge, UK and New York, NY, USA, 2001.

IPCC: Climate Change 2007: The Physical Science Basis, Contribution of Working Group I to the Forth Assessment Report of the Intergovernmental Panel on Climate Change, Cambridge University Press, Cambridge, UK and New York, NY, USA, 2007.

Kodera, K., Chiba, M., Koide, H., Kitoh, A., and Nikaidou, Y.: Interannual variability of the winter stratosphere and troposphere in the Northern Hemisphere, J. Meteorol. Soc. Jpn., 74, 365-382, 1996.

Kutiel, H. and Benaroch, Y.: North Sea-Caspian Pattern (NCP) an upper level atmospheric teleconnection affecting the Eastern Mediterranean: Identification and definition, Theor. Appl. Climatol., 71, 17-28, 2002.

Küttel, M., Xoplaki, E., Gallego, D., Luterbacher, J., GarciaHerrera, R., Allan, R., Barriendos, M., Jones, P. D., Wheeler, D., and Wanner, H.: The importance of ship log data: Reconstructing North Atlantic, European and Mediterranean sea level pressure fields back to 1750, Clim. Dynam., 34, 1115-1128, 2010. 
Legutke, S. and Voss, R.: The Hamburg Atmosphere-Ocean Coupled circulation model ECHO-G, Tech. Rep. 18, Deutsches Klimarechenzentrum, Hamburg, Germany, 62 pp., 1999.

Lehner, F., Raible, C. C., Hofer, D., and Stocker, T. F.: The freshwater balance of polar regions in transient simulations from 1500 to $2100 \mathrm{AD}$ using a comprehensive coupled climate model, Clim. Dynam., 39, 347-363, 2012a.

Lehner, F., Raible, C. C., and Stocker, T. F.: Testing the robustness of a precipitation proxy-based North Atlantic Oscillation reconstruction, Quaternary Sci. Rev., 45, 85-94, 2012b.

Lehner, F., Born, A., Raible, C. C., and Stocker, T. F.: Amplified inception of European Little Ice Age by sea ice-ocean-atmosphere feedbacks, J. Climate, 26, 7586-7602, 2013.

Lorenz, E. N.: The nature and theory of the general circulation of the atmosphere, Tech. rep., WMO-No. 218, TP 115, WMO, Geneva, Switzerland, 161 pp., 1967.

Luksch, U., Raible, C. C., Blender, R., and Fraedrich, K.: Cyclone track and decadal Northern Hemispheric regimes, Meteorol. Z., 14, 747-753, 2005.

Luterbacher, J., Schmutz, C., Gyalistras, D., Xoplaki, E., and Wanner, H.: Reconstruction of monthly NAO and EU indices back to AD 1675, Geophys. Res. Lett., 26, 2745-2748, 1999.

Luterbacher, J., Xoplaki, E., Dietrich, D., Jones, P. D., Davies, T. D., Portis, D., Gonzalez-Rouco, J. F., von Storch, H., Gyalistras, D., Casty, C., and Wanner, H.: Extending North Atlantic Oscillation reconstructions back to 1500, Atmos. Sci. Lett., 2, 114-124, 2002.

Mann, M. E.: Large-scale climate variability and connections with the Middle East in past centuries, Climatic Change, 55, 287-314, 2002.

Moore, G. W. K., Holdsworth, G., and Alverson, K.: Climate change in the North Pacific region over the past three centuries, Nature, 420, 401-403, 2002.

Moore, G. W. K., Pickart, R. S., and Renfrew, I. A.: Complexities in the climate of the subpolar North Atlantic: a case study from the winter of 2007, Q. J. Meteorol. Soc., 137, 757-767, doi:10.1002/qj.778, 2011.

Moore, G. W. K., Renfrew, I. A., and Pickart, R. S.: Multidecadal mobility of the North Atlantic Oscillation, J. Climate, 26, 2453 2466, 2013.

Olsen, J., Anderson, N. J., and Knudsen, M. F.: Variability of the North Atlantic Oscillation over the past 5,200 years, Nat. Geosci., 5, 808-812, 2012.

Pinto, J. G. and Raible, C. C.: Past and recent changes in the NAO, Interdiscip. Rev. Clim. Change, 3, 79-90, 2012.

Pinto, J. G., Reyers, M., and Ulbrich, U.: The variable link between PNA and NAO in observations and in multi-century CGCM simulations, Clim. Dynam., 36, 337-354, 2011.

Raible, C. C., Luksch, U., Fraedrich, K., and Voss, R.: North Atlantic decadal regimes in a coupled GCM simulation, Clim. Dynam., 18, 321-330, 2001.

Raible, C. C., Luksch, U., and Fraedrich, K.: Precipitation and Northern Hemisphere regimes, Atmos. Sci. Lett., 5, 43-55, 2004.

Raible, C. C., Stocker, T. F., Yoshimori, M., Renold, M., Beyerle, U., Casty, C., and Luterbacher, J.: Northern Hemispheric trends of pressure indices and atmospheric circulation patterns in observations, reconstructions, and coupled GCM simulations, J. Climate, 18, 3968-3982, 2005.
Raible, C. C., Casty, C., Luterbacher, J., Pauling, A., Esper, J., Frank, D. C., Büntgens, U., Roesch, A. C., Wild, M., Tschuck, P., Vidale, P.-L., Schär, C., and Wanner, H.: Climate variability - observations, reconstructions and model simulations, Climatic Change, 79, 9-29, 2006.

Roeckner, E., Arpe, K., and Bengtsson, L.: The atmospheric General Circulation Model ECHAM-4: Model description and simulation of present-day climate, Tech. Rep. 218, Max-PlanckInstitut, Hamburg, Germany, 90 pp., 1996.

Schmutz, C., Luterbacher, J., Gyalistras, D., Xoplaki, E., and Wanner, H.: Can we trust proxy-based NAO index reconstructions?, Geophys. Res. Lett., 27, 1135-1138, 2000.

Shabbar, A., Higuchi, K., Skinner, W., and Knox, J.: The association between the BWA index and winter surface temperature variability over eastern Canada and west Greenland, Int. J. Climatol., 17, 1195-1210, 1997.

Stephenson, D. B., Wanner, H., Broennimann, S., and Luterbacher, J.: The North Atlantic Oscillation, Climatic significance and environmental impact, Geophys. Monogr. Ser., 134, 37-50, 2003.

Taylor, K. E., Stouffer, R. J., and Meehl, G. A.: An overview of CMIP5 and the experiment design, B. Am. Meteorol. Soc., 93, 485-498, 2012.

Trouet, V. and Taylor, A. H.: Multi-century variability in the Pacific North American circulation pattern reconstructed from tree rings, Clim. Dynam., 35, 953-963, 2010.

Trouet, V., Esper, J., Graham, N. E., Baker, A., Scourse, J. D., and Frank, D. C.: Persistent positive North Atlantic Oscillation mode dominated the Medieval Climate Anomaly, Science, 324, 78 80, 2009.

Ulbrich, U. and Christoph, M.: A shift of the NAO and increasing storm track activity over Europe due to anthropogenic Greenhouse gas forcing, Clim. Dynam., 15, 551-559, 1999.

Wallace, J. M. and Gutzler, D. S.: Teleconnections in the geopotential height field during the Northern Hemisphere winter, Mon. Weather Rev., 109, 782-812, 1981.

Wanner, H., Brönnimann, S., Casty, C., Gyalistras, D., Luterbacher, J., Schmutz, C., Stephenson, D. B., and Xoplaki, E.: North Atlantic Oscillation - concepts and studies, Surv. Geophys., 22, 321-382, 2001.

Wolff, J. O., Maier-Reimer, E., and Legutke, S.: The Hamburg Ocean primitive equation model HOPE, Tech. Rep. 13, Deutsches Klimarechenzentrum, Hamburg, Germany, 1997.

Woollings, T., Charlton-Perez, A., Ineson, S., Woollings, T., Charlton-Perez, A., Ineson, S., Marshall, A. G., and Masato, G.: Associations between stratospheric variability and tropospheric blocking, J. Geophys. Res., 115, D06108, doi:10.1029/2009JD012742, 2010a.

Woollings, T. J., Hannachi, A., Hoskins, B., and Turner, B. A.: A regime view of the North Atlantic Oscillation and its response to anthropogenic forcing, J. Climate, 23, 1291-1307, 2010b.

Yeager, S. G., Shields, C. A., Large, W. G., and Hack, J. J.: The low-resolution CCSM3, J. Climate, 19, 2545-2566, 2006.

Yoshimori, M., Raible, C. C., Stocker, T. F., and Renold, M.: Simulated decadal oscillations of the Atlantic meridional overturning circulation in a cold climate state, Clim. Dynam., 34, 101-121, doi:10.1007/s00382-009-0540-9, 2010. 
Zorita, E. and Gonzalez-Rouco, F.: Are temperature-sensitive proxies adequate for North Atlantic Oscillation reconstructions?, Geophys. Res. Lett., 29, 1703, doi:10.1029/2002GL015404, 2002.

Zorita, E., Gonzalez-Rouco, J. F., and Legutke, S.: Statistical temperature reconstruction in a 1000-year-long control climate simulation an excercise with Mann's et al. (1998) method, J. Climate, 16, 1378-1390, 2003.
Zorita, E., Gonzalez-Rouco, J. F., von Storch, H., Montavez, J. P., and Valero, F.: Natural and anthropogenic modes of surface temperature variations in the last thousand years, Geophys. Res. Lett., 32, L08707, doi:10.1029/2004GL021563, 2005. 